\title{
Disrupted Regulation of Ghrelin Production Under Antihypertensive Treatment in Spontaneously Hypertensive Rats
}

\author{
Naokazu Hamada, MD; Yoshihiro Nishi, MD, PhD; Yuji Tajiri, MD, PhD; \\ Kentaro Setoyama, PhD; Ryozo Kamimura, PhD; Kenkichi Miyahara, MD, PhD; \\ Norihito Nuruki, MD, PhD; Hiroshi Hosoda, MD, PhD; Kenji Kangawa, PhD; \\ Masayasu Kojima, MD, PhD; Hiroharu Mifune, PhD
}

\begin{abstract}
Background: Ghrelin is an acylated peptide hormone mainly secreted from the stomach. When administrated externally it modulates vascular tone mainly through the regulation of autonomic nerve activity. However, the effects of blood pressure (BP) on the production and secretion of ghrelin remain to be clarified.
\end{abstract}

Methods and Results: We examined the stomach and plasma levels of ghrelin in spontaneously hypertensive (SHR) and Wistar-Kyoto (WKY) rats after a 4-week-intervention with antihypertensive agents (candesartan-cilexetil [ARB], doxazosin [DZN], metoprolol [MP], reserpine [RES]) to clarify the influence of BP on the secretion of ghrelin. The effect of these agents on ghrelin production and secretion were examined by comparing vehicle-treated controls (WKY-Intact, SHR-Intact). Treatment with the 4 antihypertensive drugs all yielded a significant decline in systolic BP in both SHR and WKY. Under these conditions, significantly lower levels of stomach and plasma ghrelin were detected in WKY treated with ARB $(\mathrm{P}<0.05)$, DZN $(\mathrm{P}<0.05)$, MP $(\mathrm{P}<0.05)$ and RES $(\mathrm{P}<0.05)$ compared with WKYIntact, whereas no significant change in the ghrelin levels in the stomach and plasma were detected in SHR under the same treatments.

Conclusions: The findings imply that the production and secretion of ghrelin are controlled by the ambient vascular tone and vice versa in normotensive WKY. This inter-relationship between ghrelin and BP seems to be disrupted in SHR. (Circ J 2012; 76: 1423-1429)

Key Words: Antihypertensive treatment; Ghrelin; Hypertension; Spontaneously hypertensive rats

G hrelin is an acylated peptide hormone mainly produced in the stomach. ${ }^{1}$ The third amino acid residue, serine (ser3), of mammalian ghrelin peptides is modified by the addition of an acyl group from fatty acids. ${ }^{2}$ This acyl-modification is essential for the biological activity of ghrelin, which is exerted through the activation of the growth hormone $(\mathrm{GH})$ secretagog-receptor (ghrelin receptor). Ghrelin functions primarily as an orexigen ${ }^{3}$ and a $\mathrm{GH}$-releasing hormone. ${ }^{1}$ Various other physiological roles have been reported, including modulation of energy metabolism, ${ }^{4}$ and regulation of the autonomic nervous system ${ }^{5,6}$ and cardiovascular system. ${ }^{7}$
On the other hand, ghrelin is known to possess an antihypertensive effect. ${ }^{8}$ It decreases the mean arterial pressure by directly affecting endothelial cells ${ }^{9}$ and vascular smooth muscle cells, ${ }^{10}$ or by working centrally to decrease the sympathetic outflow. ${ }^{11}$ In fact, the continuous antagonism of the ghrelin receptor induced the early onset of hypertension in an animal model of salt-sensitive hypertension, ${ }^{12}$ and the low levels of plasma ghrelin seen in association with obesity and insulin resistance impose an additive factor in the cascade of molecular abnormalities driving the progression of hypertension or type 2 diabetes. ${ }^{13}$ These findings indicate that ghrelin is

Received November 21, 2011; revised manuscript received January 3, 2012; accepted January 27, 2012; released online March 16 , 2012 Time for primary review: 20 days

Department of Digestive and Life-Style Related Disease, Health Research Course, Human and Environmental Sciences, Kagoshima University Graduate School of Medicine and Dental Sciences, Kagoshima (N.H., N.N.); Department of Physiology (Y.N.), Division of Endocrinology and Metabolism (Y.T.), Institute of Animal Experimentation (H.M.), Kurume University School of Medicine, Kurume; Institute of Life Science, Kurume University, Kurume (M.K.); Frontier Science Research Center, Kagoshima University, Kagoshima (K.S., R.K.); Department of Biochemistry, National Cerebral and Cardiovascular Center Research Institute, Suita (H.H., K.K.); and Division of Cardiology, Shinkyo Hospital, Kagoshima (K.M.), Japan

The first two authors contributed equally to this study (N.H., Y.N.).

Mailing address: Hiroharu Mifune, DVM, PhD, Institute of Animal Experimentation, Kurume University School of Medicine, 67 Asahi-machi, Kurume 830-0011, Japan. E-mail: mifune@med.kurume-u.ac.jp

ISSN-1346-9843 doi:10.1253/circj.CJ-11-1345

All rights are reserved to the Japanese Circulation Society. For permissions, please e-mail: cj@j-circ.or.jp 
an important factor in the integrated neuronal, hormonal and metabolic regulation of blood pressure (BP).

Conversely, there are few reports describing the influence of $\mathrm{BP}$, including antihypertensive treatment, on the plasma levels of ghrelin in animal models of hypertension. ${ }^{14-16}$ The present study investigated the effects of continuous antihypertensive treatment on the plasma levels of active ghrelin using a spontaneously hypertensive rat model (SHR/Izm) ${ }^{17,18}$ and their normotensive control, Wistar-Kyoto rats (WKY) to elucidate whether physiologically secreted ghrelin was able to regulate systemic BP. The abnormal regulation of ghrelin production in SHR is discussed as a possible mechanism of hypertension in this animal model.

\section{Methods}

\section{Animals}

Male, 6-10-week-old SHR (SHR/Izm, Japan SLC Inc, Shizuoka, Japan) and male WKY (WKY/Izm, SLC) were used in this study. All animals were maintained under controlled temperature $\left(24 \pm 1^{\circ} \mathrm{C}\right)$, humidity $(55 \pm 5 \%)$ and light conditions (lights on 07:00-19:00 hours) with free access to standard laboratory chow (CE-2, CREA Co Ltd, Osaka, Japan) and water. The samples from the rats were obtained under anesthesia induced with an intraperitoneal injection (i.p.) of sodium pentobarbital $\left(30 \mathrm{mg} / \mathrm{kg}\right.$, Nembutal ${ }^{\mathrm{TM}}$, Dainippon Pharmaceutical Co Ltd, Osaka, Japan). All experiments were conducted in accordance with the Guideline for Animal Experimentation, Kurume University.

\section{Experimental Protocol}

Male WKY and SHR (aged 6 weeks) were treated for 4 consecutive weeks with antihypertensive drugs in the drinking water: angiotensin II AT1 receptor blocker, candesartan-cilexetil (ARB $2 \mathrm{mg} \cdot \mathrm{kg}^{-1} \cdot \mathrm{day}^{-1}$; Takeda Pharmaceutical Co, Osaka, Japan; WKY-ARB or SHR-ARB); ${ }^{19} \alpha_{1}$-adrenergic blocker, doxazosin (DZN 30 mg $\cdot \mathrm{kg}^{-1} \cdot$ day $^{-1}$; Wako Pure Chemical, Osaka, Japan; WKY-DZN or SHR-DZN); ${ }^{20} \beta_{1}$-adrenagic blocker, metoprolol (MP 250 $\mathrm{mg} \cdot \mathrm{kg}^{-1} \cdot$ day $^{-1}$; Wako Pure Chemical; WKY-MP or SHR-MP). ${ }^{21}$ Intact rats on tap water without any antihypertensive agent for the same period served as controls (SHRIntact, WKY-Intact). All agents were first dissolved in distilled water, then the dispenser was filled up to the required volume with tap water. Water was changed daily for all groups of rats. Reserpine was administered by subcutaneous injection (RES $0.3 \mathrm{mg} \cdot \mathrm{kg}^{-1} \cdot \mathrm{day}^{-1}$; Daiichi Sankyo Co, Tokyo, Japan; WKYRES or SHR-RES) for the same period. ${ }^{22}$ Each group comprised 7 rats. Blood and stomach samples were obtained under the anesthesia from the rats fed ad libitum between 9:00 and 11:00 hours after the 4-week period. Body weight (BW) was monitored once per week during the follow-up period. Preliminary experiments showed that the study doses of each agent caused comparable and mild hypotensive effects in SHR. Drug concentrations in the drinking water were calculated every week based on the consumption of water needed to reach the desirable dosage of each agent. During the whole experimental period, there was no difference in the consumption of drinking water between the treated rats and control rats.

\section{Measurement of BW, Heart Weight (HW) and Systolic Blood Pressure (SBP)}

$\mathrm{BW}$ was measured weekly in the morning throughout the 4week follow-up period, together with SBP by the tail-cuff procedure (MK 2000, Muromachi-kikai Co Ltd, Tokyo, Japan). The rats were placed in an equipped holder for 5-10 min until they became calm prior to monitoring their BP with the tailcuff method. The BP data of rats that could not keep quiet during the measurement were excluded. The data with noise during the pulse wave monitoring of BP were also excluded. $\mathrm{BP}$ values obtained from 3 consecutive measurements of the respective rats were averaged and recorded at each time point. Hearts were weighed at the time of death and HW/BW ratios were calculated.

\section{Blood Sampling and Biochemical Analysis}

Blood samples were obtained by heart puncture into fluoride tubes for blood glucose, EDTA-2Na tubes for insulin and noradrenaline (NA), and EDTA-2Na $(1 \mathrm{mg} / \mathrm{ml})$ tubes with aprotinin $(1,000$ kallikrein inactivator units $/ \mathrm{ml})$ for ghrelin measurement. After centrifugation $\left(3,500 \mathrm{rpm}\right.$ for $15 \mathrm{~min}$ at $\left.4^{\circ} \mathrm{C}\right)$, plasma glucose was measured by a standard method, and the concentration of plasma insulin was measured by enzymelinked immunosorbent assay using a commercially available kit (Morinaga Biochemical Research Laboratory, Yokohama, Japan). Homeostasis model assessment of insulin resistance (HOMA-R) was calculated according to the formula: [plasma glucose $(\mathrm{mg} / \mathrm{dl})] \times[$ plasma insulin $(\mu \mathrm{U} / \mathrm{ml})] / 405 .{ }^{23}$

The concentration of plasma NA was determined by highperformance liquid chromatography with electrochemical detection (HPLC-ECD), as previously described. ${ }^{24}$ Briefly, the plasma protein was precipitated with trichloroacetic acid, and catecholamines were absorbed with alumina. After elution with hydrochloric acid $(\mathrm{HCl})$, the concentration of plasma NA was determined using HPLC-ECD. The HPLC system was constructed with a pump (655A-11, Hitachi) and an electrochemical detector (Model 5100A, ESA). The analysis was performed on the column: Nuclesil $7 \mathrm{C} 18(30 \mathrm{~cm} 34.6 \mathrm{~mm}$ I.D.). The mobile phase of the assay consisted of $0.1 \mathrm{~mol} / \mathrm{L}$ $\mathrm{Na}_{2} \mathrm{HPO}_{4}$ (pH 4.0), $12.5 \%$ methanol, 0.01\% EDTA-2Na and $1.25 \mathrm{mmol} / \mathrm{L} \mathrm{SOS}$ at a flow rate of $1.0 \mathrm{ml} / \mathrm{min}$.

\section{Immunohistochemistry of Ghrelin-Immunopositive Cells in the Stomach}

The stomach samples were prepared for the immunohistochemical study as described previously. ${ }^{25}$ In brief, the fundi of the rats' stomachs were dissected and fixed in Zamboni's solution for 2 days at $4^{\circ} \mathrm{C}$. The fundi were washed in $0.15 \mathrm{~mol} / \mathrm{L}$ phosphate-buffered saline (PBS, $\mathrm{pH} 7.4)$ at $4{ }^{\circ} \mathrm{C}$, and routinely embedded in paraffin and $3-\mu \mathrm{m}$-thick sections were cut every $30 \mu \mathrm{m}$. The deparaffinized and rehydrated sections were incubated in $0.3 \% \mathrm{H}_{2} \mathrm{O}_{2}$ for $30 \mathrm{~min}$ at room temperature, and blocked with 20\% normal swine serum (DAKO, Glostrup, Denmark) in PBS for $60 \mathrm{~min}$ at room temperature prior to immunohistochemical staining. The sections were incubated with rabbit antiserum against active, $n$-octanoyl ghrelin (O-ghrelin), diluted 1:100,000 (the same antiserum used for the ghrelin radioimmunoassay [RIA]) with PBS containing $0.02 \%$ Triton $\mathrm{X}-100$ overnight at $4^{\circ} \mathrm{C}$. Further incubation was performed with biotinylated swine anti-rabbit immunoglobulin (diluted 1:200; DAKO) and the sections were then treated with peroxidase-conjugated avidin-biotin complex (DAKO Cytomation ABC complex/HRP ${ }^{\mathrm{TM}}$, DAKO). After each step, the sections were rinsed thoroughly in PBS. Staining for peroxidase was performed using 4\% 3, 3'-diaminobenzidine- $0.004 \%$ $\mathrm{H}_{2} \mathrm{O}_{2}$ in Tris- $\mathrm{HCl}$ buffer ( $\mathrm{pH}$ 7.6) and the sections were counterstained with Meyer's hematoxylin. Negative control studies were performed with anti-O-ghrelin antiserum that had been absorbed by $10 \mu \mathrm{g}$ synthesized rat $\mathrm{O}$-ghrelin. ${ }^{1}$ These negative controls showed no indication of immunoreactivity.

In total, 20 sections from each control and fasted rat were 


\begin{tabular}{|c|c|c|c|c|c|}
\hline & \multirow{2}{*}{ None (Intact) } & \multicolumn{4}{|c|}{ Antihypertensive treatment } \\
\hline & & ARB & DZN & MP & RES \\
\hline \multicolumn{6}{|l|}{ BW (g) } \\
\hline WKY & $301.6 \pm 11.4$ & $294.7 \pm 17.1$ & $296.9 \pm 7.8$ & $294.4 \pm 7.1$ & $246.6 \pm 10.1^{\star \star *}$ \\
\hline SHR & $275.1 \pm 10.6^{\$}$ & $281.0 \pm 10.1$ & $273.6 \pm 9.6^{\$}$ & $261.4 \pm 8.3^{\$}$ & $188.0 \pm 9.7^{\star \star \star, \$}$ \\
\hline \multicolumn{6}{|c|}{$\mathrm{SBP}(\mathrm{mmHg})$} \\
\hline WKY & $121.3 \pm 4.7$ & $105.3 \pm 3.8^{\star *}$ & $111.7 \pm 4.7^{*}$ & $110.7 \pm 4.9^{*}$ & $108.4 \pm 5.0^{*}$ \\
\hline SHR & $196.7 \pm 9.8^{\$}$ & $114.7 \pm 4.2^{* * *, \$}$ & $128.4 \pm 7.2^{\star * *, \dagger}$ & $131.1 \pm 4.7^{\star * *, \$}$ & $126.0 \pm 5.7^{\star * *, \$}$ \\
\hline \multicolumn{6}{|c|}{ HW/BW (\%) } \\
\hline WKY & $0.295 \pm 0.016$ & $0.293 \pm 0.010$ & $0.288 \pm 0.014$ & $0.284 \pm 0.018$ & $0.358 \pm 0.015^{\star * *}$ \\
\hline SHR & $0.378 \pm 0.014^{\$}$ & $0.334 \pm 0.017^{\$}$ & $0.367 \pm 0.020^{\$}$ & $0.365 \pm 0.019^{\$}$ & $0.498 \pm 0.011^{* \star *, \$}$ \\
\hline \multicolumn{6}{|c|}{ HOMA-R } \\
\hline WKY & $1.58 \pm 0.27$ & $1.65 \pm 0.29$ & $1.56 \pm 0.38$ & $1.63 \pm 0.29$ & $1.53 \pm 0.32$ \\
\hline SHR & $2.36 \pm 0.31^{\$}$ & $2.04 \pm 0.25$ & $1.99 \pm 0.27$ & $1.95 \pm 0.29$ & $1.78 \pm 0.33^{*}$ \\
\hline \multicolumn{6}{|c|}{ Plasma NA (nmol/ml) } \\
\hline WKY & $2.56 \pm 0.53$ & $2.52 \pm 0.47$ & $2.78 \pm 0.44$ & $2.69 \pm 0.55$ & $1.87 \pm 0.39$ \\
\hline SHR & $4.63 \pm 0.79^{\$}$ & $3.64 \pm 0.87^{\#}$ & $3.75 \pm 0.79^{\#}$ & $3.17 \pm 0.81^{*}$ & $1.64 \pm 0.44^{\star \star \star}$ \\
\hline
\end{tabular}

Four-week treatment with 4 types of antihypertensive agent: angiotensin II receptor blocker, candesartan-cilexetil (ARB); an $a_{1}$-adrenergic blocker, doxazosin (DZN); a $\beta_{1}$-adrenergic blocker, metoprolol (MP); and reserpine (RES). Values are means $\pm S D$. ${ }^{*} P<0.05,{ }^{\star \star} P<0.01,{ }^{\star \star \star} P<0.001$ vs. Intact rats of the same strain; ${ }^{~} P<0.05,{ }^{\dagger} P<0.01,{ }^{\$} P<0.001$ vs. WKY of the same treatment.

SHR spontaneously hypertensive rat; WKY, Wistar-Kyoto rat; Intact, no treatment; BW, body weight; SBP, systolic blood pressure; HW/BW, the ratio of heart weight to body weight; HOMA-R, homeostasis model assessment of insulin resistance; NA, noradrenaline.

randomly examined using an ocular micrometer. The number of immunopositive cells for O-ghrelin (ip-O-ghrelin) in the stomach per unit area of the mucosal portion $\left(\mathrm{mm}^{2}\right)$ was counted using a software system (Meta Morph, Molecular Devices Co Ltd, Tokyo, Japan).

\section{Preparation of Plasma and Stomach Samples for Ghrelin RIA} The stomach and plasma samples from rats were prepared as described previously. ${ }^{26}$ In brief, the whole stomach was dissected from the rat and washed twice in $50 \mathrm{mmol} / \mathrm{L}$ PBS $(\mathrm{pH}$ 7.4) and weighed. Each stomach sample was boiled for $5 \mathrm{~min}$ in 10-fold volume of water $\left(>95^{\circ} \mathrm{C}\right)$ to inactivate intrinsic proteases soon after the dissection (within $1 \mathrm{~min}$ ). The samples were cooled on ice, and acetic acid $(\mathrm{AcOH})$ and $\mathrm{HCl}$ were added to make a final concentration of $1.0 \mathrm{~mol} / \mathrm{L} \mathrm{AcOH} /$ $20 \mathrm{mmol} / \mathrm{L} \mathrm{HCl}$. The boiled tissue in acidified solution was homogenized and the supernatant was isolated, lyophilized and stored at $-80^{\circ} \mathrm{C}$ until assay for $\mathrm{O}$-ghrelin. Each sample of whole blood from the respective rat, fed ad libitum, was obtained by heart puncture, and immediately transferred to chilled polypropylene tubes containing EDTA-2Na $(1 \mathrm{mg} / \mathrm{ml})$ and aprotinin (1,000 kallikrein inactivator units $/ \mathrm{ml})$ and centrifuged at $4{ }^{\circ} \mathrm{C}$. The plasma was separated and $\mathrm{HCl}$ was added to a final concentration of $1.0 \mathrm{~N}$, and the acidified plasma was diluted with an equal volume of $0.9 \% \mathrm{NaCl}$ solution. The plasma samples were prepared within 5 min after sampling the rats. Each pretreated plasma sample was extracted using a SepPak Plus ${ }^{\mathrm{TM}} \mathrm{C} 18$ cartridge (Waters, Milford, MA, USA) with a $60 \% \mathrm{CH}_{3} \mathrm{CN}-0.1 \%$ trifluoro-acetic acid solution. The extract was lyophilized after evaporating the $\mathrm{CH}_{3} \mathrm{CN}$ and stored at $-80^{\circ} \mathrm{C}$ until assay for O-ghrelin.

\section{RIA for Ghrelin}

The RIA for active, $n$-octanoyl ghrelin (O-ghrelin), which mainly recognizes the $\mathrm{N}$-terminal sequence of active ghrelin, was performed as described previously. ${ }^{27}$ All assays were done in duplicate. The immunoreactivity of $\mathrm{O}$-ghrelin in each sample was measured after a serial dilution, to fit the range of measurement (between $\mathrm{ED}_{80}$ to $\mathrm{ED}_{20}$ ) in the RIA buffer [50 mmol/L sodium phosphate buffer $(\mathrm{pH} 7.4), 0.25 \%$ bovine serum albumin, $0.5 \%$ Triton $\mathrm{X}-100,80 \mathrm{mmol} / \mathrm{L} \mathrm{NaCl}$ and $25 \mathrm{mmol} / \mathrm{L}$ EDTA-2Na] containing $0.5 \%$ normal rabbit serum. The minimum detection level by this assay was $0.25 \mathrm{fmol} / \mathrm{tube}$. The intra- and the interassay coefficients of variation of this RIA were $3.0 \%$ and $5.0 \%$, respectively.

\section{Reverse Transcription-Polymerase Chain Reaction (PCR) for mRNAs of Ghrelin}

The expression levels of ghrelin mRNA in the stomachs of the rats were examined by semi-quantitative reverse transcriptionPCR as described previously. ${ }^{16}$ PCR was performed with a commercially available PCR kit (Go-Taq Master MixTM: Promega, Madison, WI, USA) with each primer set to amplify the transcripts for ghrelin (Accession No. NM_021669, 32 cycles). NIHimage (http://rsb.info.nih.gov/nih-image) was used to determine the relative amount of each PCR product after gel electrophoresis and normalized by the simultaneously amplified $\beta$-actin.

\section{Statistical Analysis}

All statistical tests were performed using SAS ver. 9.2 (SAS Institute Inc, Cary, NC, USA). Data were analyzed by 1-way ANOVA for comparisons between groups and expressed as means \pm SD. Significances among groups were further verified by a post hoc test (Scheffe's F-test). Differences within a group before and after treatment were assessed by paired t-test. $\mathrm{P}<0.05$ was considered as statistically significant.

\section{Results}

BW, SBP, HW/BW, HOMA-IR, and Plasma Concentration of NA Following Antihypertensive Treatment (Table)

The BW of the intact SHR was significantly lower than that of 

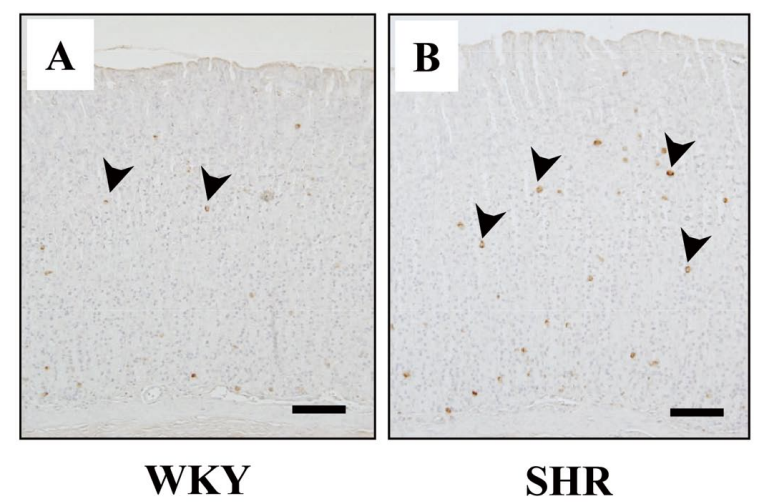

C

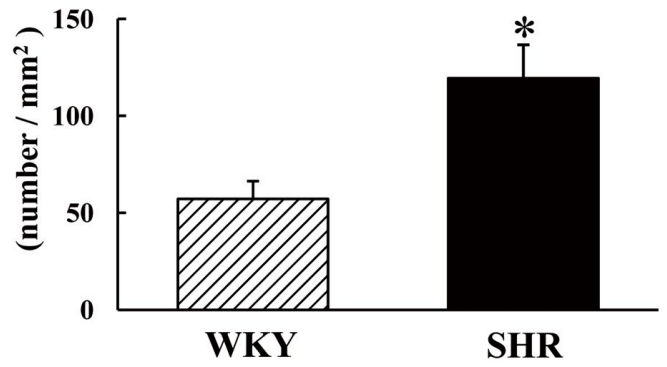

Figure 1. Localization of ghrelin-immunopositive cells (ipghrelin cells) in the stomach mucosa of both untreated WKY (10-week-old, A) or SHR (10-week-old, B), together with the number of ip-ghrelin cells per unit area $\left(\mathrm{mm}^{2}\right)$ in the gastric mucosa of WKY or SHR (C). Scale bar $=100 \mu \mathrm{m}$. Values represent the means $\pm S D$. $(n=10)$. ${ }^{*} P<0.05$ vs. WKY. SHR, spontaneously hypertensive rat; WKY, Wistar-Kyoto rat.

intact WKY. The 4-week antihypertensive treatments did not affect BW, except for reserpine, which caused a significant weight reduction in both strains of rats. From 6 to 10 weeks old, a marked increase in SBP in the intact SHR (108.1 \pm 7.6 to $196.7 \pm 9.8 \mathrm{mmHg}, \mathrm{P}<0.001)$ and a modest but significant increase in the intact WKY $(105.3 \pm 8.2$ to $121.3 \pm 4.7 \mathrm{mmHg}$, $\mathrm{P}<0.01)$ were observed. The 4 -week antihypertensive treatment resulted in a significant reduction in SBP in both SHR and WKY with any type of drug. The SBP values for the SHR-ARB, -DZN, -MP, and -RES groups were still significantly higher compared with those for WKY on the same treatments.

The HW/BW values of the SHR were significantly higher than those of the WKY on the same treatment, irrespective of the type of antihypertensive drug. The HW/BW values of both WKY-RES and SHR-RES were significantly greater than those of the other treatment groups and the untreated control groups of the same strain of rat.

Untreated SHR showed insulin resistance as expressed by HOMA-R compared with untreated WKY. After the 4-week antihypertensive treatment, the insulin resistance state was ameliorated and the significant differences in HOMA-R between SHR and WKY disappeared irrespective of the treatment. However, only SHR-RES showed a significant decrease in this index compared with the untreated SHR. The plasma NA concentration in untreated SHR was significantly higher compared with WKY, and this accelerated NA concentration was ameliorated by treatment with MP or RES.

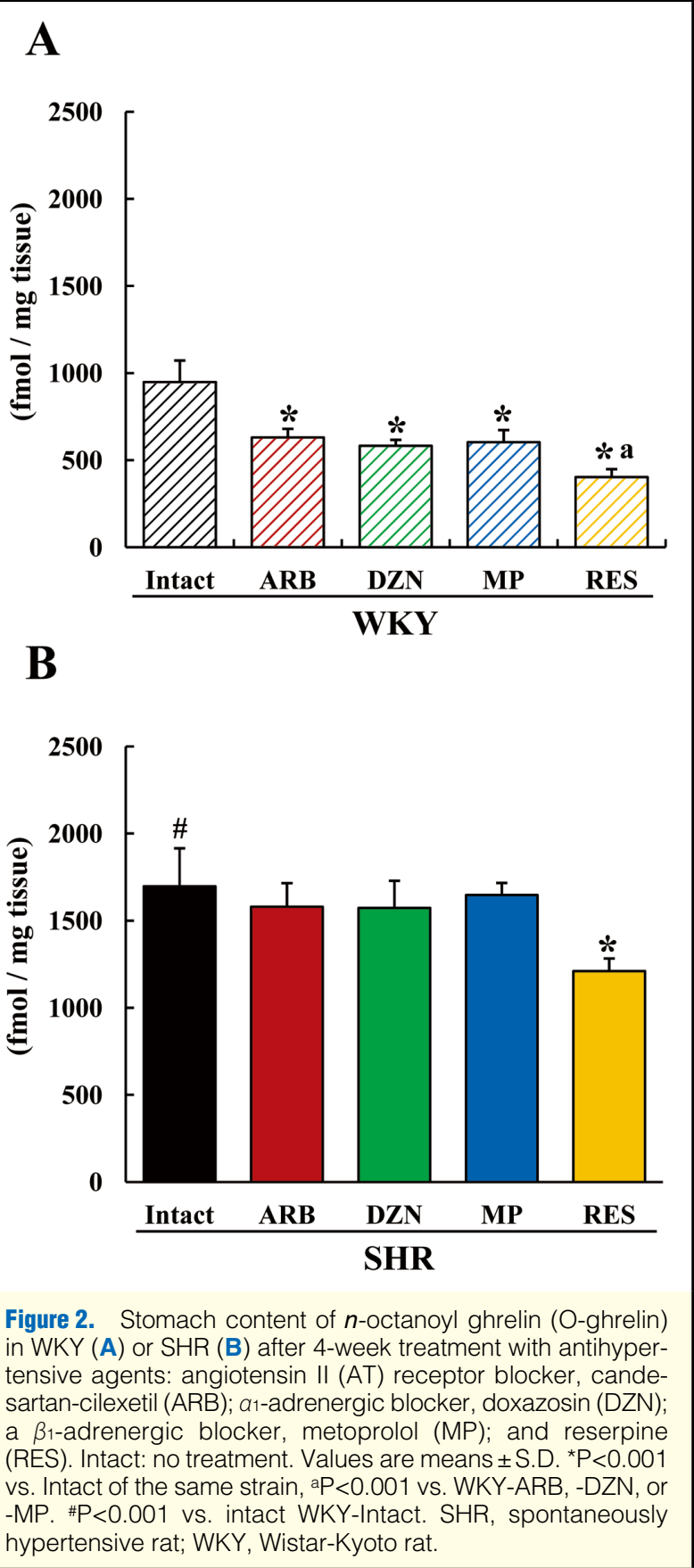

\section{Ghrelin-Producing Cells of the Stomach in SHR With Hypertension}

Ghrelin-immunopositive cells (ip-ghrelin cells) in the stomach of both untreated WKY (Figure 1A) and SHR (Figure 1B) were sparsely distributed in the lower part of the gastric mucosal layer, where they were moderately abundant. The density of ip-ghrelin cells in SHR was greater than that in WKY rat. The number of ip-ghrelin cells per unit area of the stomach mucosa $\left(\mathrm{mm}^{2}\right)$ in SHR $(120.4 \pm 5.4)$ was significantly larger than the number of ip-ghrelin cells in the same unit area of the stomach mucosa in WKY (57.2 \pm 2.9 ; Figure 1C). 

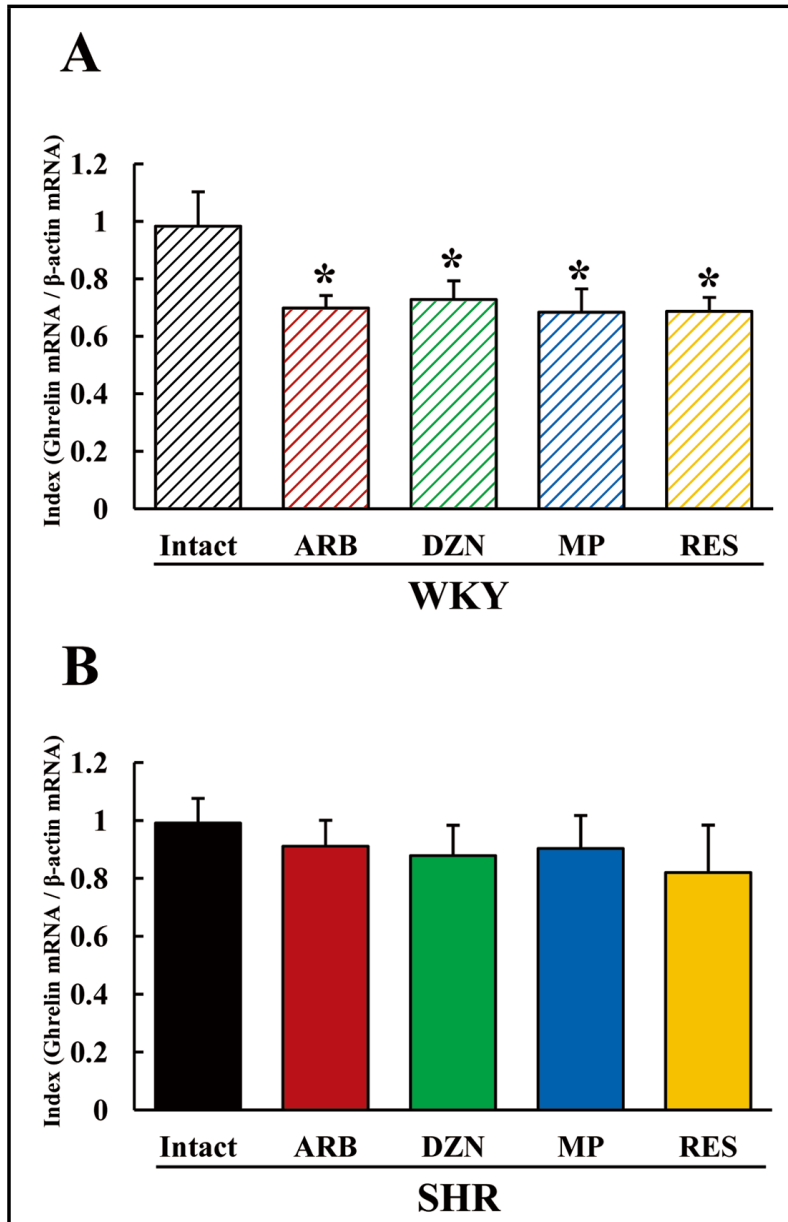

Figure 3. Stomach ghrelin mRNA expression in WKY (A) or SHR (B) after 4-week treatment with antihypertensive agents: angiotensin II (AT) receptor blocker, candesartan-cilexetil (ARB); a1-adrenergic blocker, doxazosin (DZN); $\beta_{1}$-adrenergic blocker, metoprolol (MP); and reserpine (RES). Intact: no treatment. Values are means $\pm S D$. ${ }^{*} P<0.01$ vs. WKY-Intact. SHR, spontaneously hypertensive rat; WKY, Wistar-Kyoto rat.

\section{Stomach Content of O-Ghrelin in SHR and WKY Rats Following Antihypertensive Treatment}

As shown in Figure 2, the stomach content of O-ghrelin, in untreated SHR-Intact was significantly higher than in WKYIntact. In the WKY groups, the stomach content of active ghrelin was significantly reduced in association with the antihypertensive treatments regardless of the type of drug. The stomach content in WKY-RES was further decreased compared with that in WKY-ARB, WKY-DZN, and WKY-MP. In contrast, no significant changes in this parameter were observed after the 4-week antihypertensive treatments in the SHR groups other than SHR-RES in which there was a significant reduction compared with the other groups of the same strain.

\section{Stomach Ghrelin mRNA Expression in SHR and WKY Rats Following Antihypertensive Treatment}

Similar to the changes in stomach O-ghrelin content, the relative mRNA levels of ghrelin in the WKY groups were significantly reduced after the 4-week treatment with antihypertensive agents regardless of the type of drug (Figure 3A). Again, no significant change in the stomach ghrelin mRNA

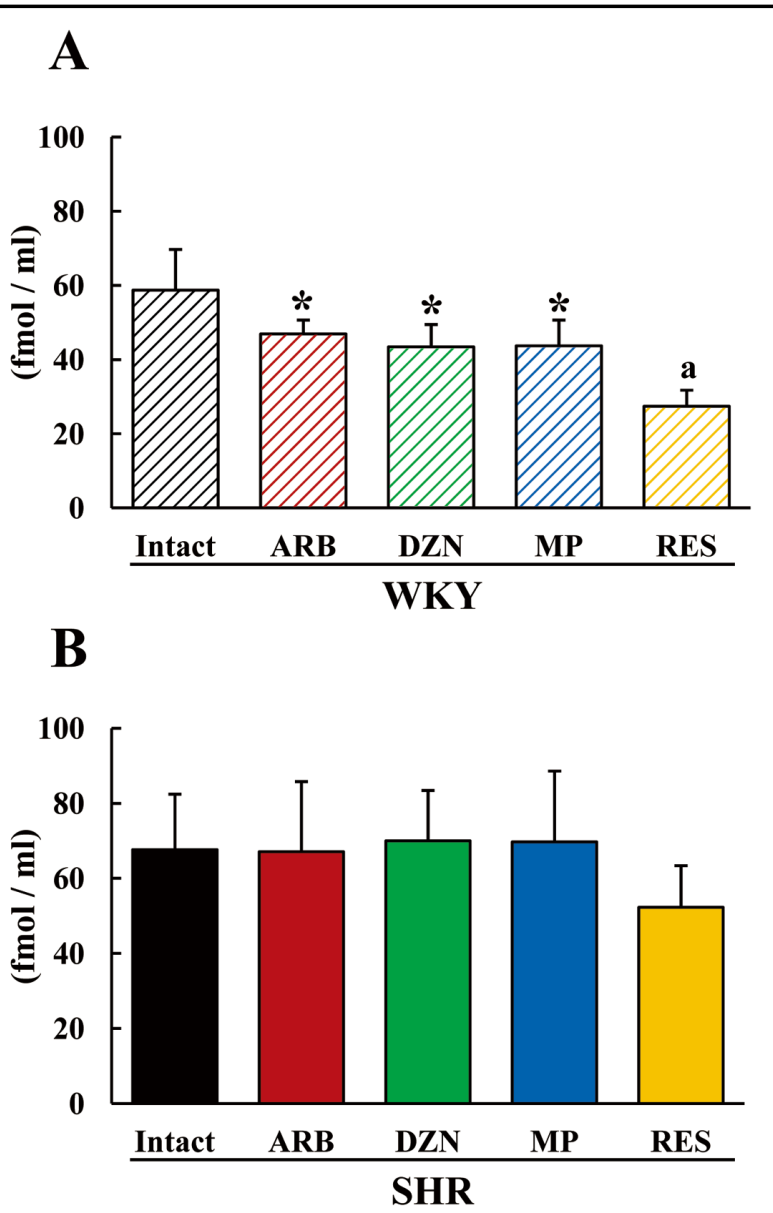

Figure 4. Plasma concentrations of $n$-octanoyl ghrelin (Oghrelin) in WKY (A) or SHR (B) after 4-week treatment with antihypertensive agents: angiotensin II (AT) receptor blocker, candesartan-cilexetil (ARB); a1-adrenergic blocker, doxazosin (DZN); $\beta$-adrenergic blocker, metoprolol (MP); and reserpine (RES). Intact: no treatment. Values are means $\pm S D$. ${ }^{*} P<0.05$ vs. WKY-Intact, aP $<0.001$ vs. WKY-Intact, -ARB, -DZN, -MP. SHR, spontaneously hypertensive rat; WKY, Wistar-Kyoto rat.

expression was observed in SHR associated with antihypertensive treatments (Figure 3B).

\section{Plasma Concentrations of Active Ghrelin in SHR and WKY Rats Following Antihypertensive Treatment}

Plasma ghrelin concentrations in WKY after antihypertensive treatment showed an analogous pattern to stomach ghrelin content in the same strain; that is, a significant decrease was observed with all types of agents, especially reserpine. However, no significant differences were detected in the plasma O-ghrelin concentrations in SHR after antihypertensive treatment in the same manner as stomach ghrelin content and mRNA expression (Figure 4).

\section{Discussion}

There are 3 major findings of the current study. First, ghrelin production and secretion are accelerated in hypertensive SHR in comparison with normotensive WKY. Second, SBP was significantly decreased after antihypertensive treatment in SHR as well as WKY irrespective of drug type. Finally, anti- 
hypertensive treatment effectively suppressed ghrelin production in WKY irrespective of the type of treatment, but this suppressive effect was disrupted in SHR. The antihypertensive treatments did not affect BW in either WKY or SHR, except for reserpine (SHR-RES, WKY-RES) for which a significant weight reduction was observed, thus indicating that the nutritional conditions were not influenced by the treatment with ARB, DZN and MPL.

The number of ghrelin-immunopositive cells (ip-ghrelin cells) was greater without any antihypertensive treatment, and the ghrelin content was higher in the stomachs of SHR than in those of WKY. These findings are consistent with previous reports that demonstrated the increased production rate of ghrelin in the stomachs of SHR. ${ }^{14,15}$ Furthermore, the fasting plasma ghrelin concentration has been found to be significantly higher in patients with pregnancy-induced hypertension than in normally pregnant women. ${ }^{28}$ These results suggest that ghrelin may play an important role in the regulation of BP.

The stomach ghrelin contents in WKY declined significantly after treatment with antihypertensive agents (ARB, DZN, MP and RES) in comparison with the untreated WKY, with a simultaneous decrease in SBP in those treatment groups. Ghrelin mRNA expression in WKY also declined significantly after treatment with all 4 drugs. Despite different pharmacological mechanisms of lowering BP, all 4 antihypertensive agents reduced the stomach content of ghrelin in WKY through decelerating the production rate of ghrelin. These findings strengthen the hypothesis that both ghrelin and vascular tone mutually interact through the autonomic nervous system for the regulation of BP. This concept is partially supported by previous findings that the secretion of ghrelin from the stomach is under the control of the sympathetic ${ }^{29,30}$ and parasympathetic systems. ${ }^{31,32}$ Conversely, the ghrelin receptor, ${ }^{33}$ as well as the receptors for angiotensin $\mathrm{II}^{34}$ are expressed in the neuronal cells of the nodose ganglion, through which the vagal afferent nerve transmits its signals to the nucleus of the solitary tract (NTS). Ghrelin may also participate in the neurohormonal regulation of BP through this vagal afferent system $^{5,11}$ and other regions. ${ }^{35}$ In fact, peripherally administrated ghrelin modulated NTS and the dorsal motor nucleus of the vagal nerve, ${ }^{36}$ and these autonomic nerve components are among the important neuronal factors in the regulation of BP. ${ }^{37}$ The reason for the lower ghrelin levels after treatment with RES in comparison with the other antihypertensive agents (ARB, DZN, MP) might be partly because of the effect of RES on feeding behavior and/or the nutritional condition of WKY. In fact, a significant decline in BW was observed in RES-treated rats than in the other antihypertensive treatment groups. From these findings with RES-treated animals, we should also consider that changes in ghrelin production and secretion may be dependent on feeding and/or nutritional conditions, which could be influenced in the setting of antihypertensive treatment and thus changes in BP.

In contrast to the finding in WKY, there was no significant difference in the stomach ghrelin content, the plasma ghrelin concentration or the stomach ghrelin mRNA expression in SHR treated with or without antihypertensive agents, despite the marked decrease in SBP after the antihypertensive treatments. Pro-inflammatory conditions in the NTS, ${ }^{38}$ as well as an abnormality within the angiotensin II-eNOS system in the NTS,${ }^{39}$ are thought to be involved in the development of hypertension in SHR via a derangement of the baroreceptor reflex $^{40}$ or the set point control of BP. ${ }^{41}$ Those anomalies of parasympathetic (vagal) input and sympathetic outflow in SHR may account for the disruption in the stomach and plasma levels of ghrelin associated with the change in arterial BP induced by the antihypertensive treatments. It is interesting that the plasma NA concentrations in SHR were still higher after antihypertensive treatment, except for MP and RES, compared with WKY on the same treatments, despite the significant reductions in BP, suggesting a possible disruption of the interaction between ghrelin and the autonomic nerve system.

Skoczylas et al recently reported an increase in the plasma ghrelin levels in obese hypertensive patients after antihypertensive treatment with ACE-inhibitor (cilazapril).42 insulin resistance and obesity are known to be inversely related to the plasma ghrelin concentration. ${ }^{43}$ An improvement in insulin resistance has also been noted in human subjects after treatment with ACE-inhibitor, which seems to account for the increased plasma ghrelin levels after this antihypertensive treatment. SHR, which are used as an animal model for naturally occurring hypertension, also possess the potential for insulin resistance. ${ }^{44}$ In fact, the current study revealed increased insulin resistance expressed as HOMA-R in untreated SHR in comparison with untreated WKY. In the present study, the insulin resistance condition in SHR was partially but not significantly ameliorated by the antihypertensive treatments other than RES. Indeed, it is possible that this amelioration of insulin resistance accounts for the increase in ghrelin production and thus the disrupted ghrelin suppression after the antihypertensive treatments in SHR. Very recently, overfeeding-induced obesity in SHR has been reported to be an animal model of the human metabolic syndrome with hypertension. ${ }^{45}$ It would be intriguing to use this animal model to study the interaction between the control of energy metabolism and that of BP in relation to the neurohormonal regulation exerted by ghrelin.

\section{Conclusion}

This study investigated the changes in the levels of stomach and plasma ghrelin after antihypertensive treatments in SHR and WKY. BP seems to modulate the production and secretion processes of ghrelin in WKY, thus indicating that naturally secreted ghrelin plays a role in the neurohormonal regulation of BP. SHR, an animal model of central (neuronal) hypertension, also demonstrated a disruption in this neurohormonal control of ghrelin production and secretion. However, it is still unclear whether these effects on ghrelin production were attributable solely to the fall in BP or to some other indirect mechanism such as amelioration of insulin resistance, and future studies are anticipated to clarify this important issue.

\section{Acknowledgments}

This work was supported in part by Grants-in aid for Scientific Research (C) (No. 19590840 \& 22500361) from the Ministry of Education, Culture, Sports, Science and Technology of Japan.

\section{Disclosure}

Conflict of interest: There is no conflict of interest for this study.

\section{References}

1. Kojima M, Hosoda H, Date Y, Nakazato M, Matsuo H, Kangawa K Ghrelin is a growth-hormone-releasing acylated peptide from stomach. Nature 1999; 402: 656-660.

2. Kojima M, Kangawa K. Ghrelin: Structure and function. Physiol Rev 2005; 85: 495-522.

3. Nakazato M, Murakami N, Date Y, Kojima M, Matsuo H, Kangawa $\mathrm{K}$, et al. A role for ghrelin in the central regulation of feeding. Nature 2001; 409: 194-198.

4. De Vriese C, Perret J, Delporte C. Focus on the short- and long-term effects of ghrelin on energy homeostasis. Nutrition 2010; 26: 579- 
584.

5. Matsumura K, Tsuchihashi T, Fujii K, Abe I, Iida M. Central ghrelin modulates sympathetic activity in conscious rabbits. Hypertension 2002; 40: 694-699.

6. Date Y, Shimbara T, Koda S, Toshinai K, Ida T, Murakami N, et al. Peripheral ghrelin transmits orexigenic signals through the noradrenergic pathway from the hindbrain to the hypothalamus. Cell Metab 2006; 4: $323-331$

7. Tesauro M, Schinzari F, Caramanti M, Lauro R, Cardillo C. Cardiovascular and metabolic effects of ghrelin. Curr Diabetes Rev 2010; 6: $228-235$.

8. Nagaya N, Kojima M, Uematsu M, Yamagishi M, Hosoda H, Oya $\mathrm{H}$, et al. Hemodynamic and hormonal effects of human ghrelin in healthy volunteers. Am J Physiol Regul Integr Comp Physiol 2001; 280: R1483-R1487.

9. Okumura H, Nagaya N, Enomoto M, Nakagawa E, Oya H, Kangawa $\mathrm{K}$. Vasodilatory effect of ghrelin, an endogenous peptide from the stomach. J Cardiovasc Pharmacol 2002; 39: 779-783.

10. Wiley KE, Davenport AP. Comparison of vasodilators in human internal mammary artery: Ghrelin is a potent physiological antagonist of endothelin-1. Br J Pharmacol 2002; 136: 1146-1152.

11. Lin Y, Matsumura K, Fukuhara M, Kagiyama S, Fujii K, Iida M. Ghrelin acts at the nucleus of the solitary tract to decrease arterial pressure in rats. Hypertension 2004; 43: 977-982.

12. Sato T, Nakashima Y, Nakamura Y, Ida T, Kojima M. Continuous antagonism of the ghrelin receptor results in early induction of saltsensitive hypertension. J Mol Neurosci 2011; 43: 193-199.

13. Garcia EA, Korbonits M. Ghrelin and cardiovascular health. Curr Opin Pharmacol 2006; 6: 142-147.

14. Raso GM, Bianco G, Iacono A, Esposito E, Autore G, Ferrante MC, et al. Maternal adaptations to pregnancy in spontaneously hypertensive rats: Leptin and ghrelin evaluation. J Endocrinol 2007; 194: 611-619.

15. Li ZF, Guo ZF, Cao J, Hu JQ, Zhao XX, Xu RL, et al. Plasma ghrelin and obestatin levels are increased in spontaneously hypertensive rats. Peptides 2010; 31: 297-300.

16. Nonoshita A, Nishi Y, Takushima S, Oshima M, Hosoda H, Kangawa $\mathrm{K}$, et al. Dynamics of placental ghrelin production and its receptor expression in a Dahl salt-sensitive rat model of intrauterine growth restriction. Placenta 2010; 31: 358-364.

17. Han J, Jiang DM, Du CQ, Hu SJ. Alteration of enzyme expressions in mevalonate pathway: Possible role for cardiovascular remodeling in spontaneously hypertensive rats. Circ J 2011; 75: 1409-1417.

18. Ariyoshi K, Maruyama T, Odashiro K, Akashi K, Fujino T, Uyesaka $\mathrm{N}$. Impaired erythrocyte filterability of spontaneously hypertensive rats: Investigation by nickel filtration technique. Circ J 2010; 74: $129-136$.

19. You D, Loufrani L, Baron C, Levy BI, Widdop RE, Henrion D. High blood pressure reduction reverses angiotensin II type 2 receptor-mediated vasoconstriction into vasodilation in spontaneously hypertensive rats. Circulation 2005; 111: 1006-1011.

20. Reddi AS, Nimmagadda VR, Lefkowitz A, Kuo HR, Bollineni JS. Effect of antihypertensive therapy on renal injury in type 2 diabetic rats with hypertension. Hypertension 2000; 36: 233-238.

21. Chan V, Fenning A, Hoey A, Brown L. Chronic beta-adrenoceptor antagonist treatment controls cardiovascular remodeling in heart failure in the aging spontaneously hypertensive rat. $J$ Cardiovasc Pharmacol 2011; 58: 424-431.

22. Matsuu M, Shichijo K, Nakamura Y, Ikeda Y, Naito S, Ito M, et al. The role of the sympathetic nervous system in radiation-induced apoptosis in jejunal crypt cells of spontaneously hypertensive rats. $J$ Radiat Res (Tokyo) 2000; 41: 55-65.

23. Matthews DR, Hosker JP, Rudenski AS, Naylor BA, Treacher DF, Turner RC. Homeostasis model assessment: Insulin resistance and beta-cell function from fasting plasma glucose and insulin concentrations in man. Diabetologia 1985; 28: 412-419.

24. Taylor RB, Reid R, Kendle KE, Geddes C, Curle PF. Assay proce- dures for the determination of biogenic amines and their metabolites in rat hypothalamus using ion-pairing reversed-phase high-performance liquid chromatography. J Chromatogr 1983; 277: 101-114.

25. Yabuki A, Ojima T, Kojima M, Nishi Y, Mifune H, Matsumoto M, et al. Characterization and species differences in gastric ghrelin cells from mice, rats and hamsters. J Anat 2004; 205: 239-246.

26. Nishi Y, Hiejima H, Mifune H, Sato T, Kangawa K, Kojima M. Developmental changes in the pattern of ghrelin's acyl modification and the levels of acyl-modified ghrelins in murine stomach. Endocrinology 2005; 146: 2709-2715.

27. Nishi Y, Hiejima H, Hosoda H, Kaiya H, Mori K, Fukue Y, et al. Ingested medium-chain fatty acids are directly utilized for the acyl modification of ghrelin. Endocrinology 2005; 146: 2255-2264.

28. Makino Y, Hosoda H, Shibata K, Makino I, Kojima M, Kangawa K, et al. Alteration of plasma ghrelin levels associated with the blood pressure in pregnancy. Hypertension 2002; 39: 781-784.

29. Mundinger TO, Cummings DE, Taborsky GJ Jr. Direct stimulation of ghrelin secretion by sympathetic nerves. Endocrinology 2006; 147: $2893-2901$.

30. Zhao TJ, Sakata I, Li RL, Liang G, Richardson JA, Brown MS, et al. Ghrelin secretion stimulated by $\beta_{1}$-adrenergic receptors in cultured ghrelinoma cells and in fasted mice. Proc Natl Acad Sci USA 2010; 107: $15868-15873$.

31. Hosoda $\mathrm{H}$, Kangawa $\mathrm{K}$. The autonomic nervous system regulates gastric ghrelin secretion in rats. Regul Pept 2008; 146: 12-18.

32. Maier C, Riedl M, Vila G, Nowotny P, Wolzt M, Clodi M, et al. Cholinergic regulation of ghrelin and PYY release may be impaired in obesity. Diabetes 2008; 57: 2332-2340.

33. Sato M, Nakahara K, Miyazato M, Kangawa K, Murakami N. Regulation of GH secretagogue receptor gene expression in the rat nodose ganglion. J Endocrinol 2007; 194: 41-46.

34. Allen AM, Lewis SJ, Verberne AJ, Mendelsohn FA. Angiotensin receptors and the vagal system. Clin Exp Hypertens A 1988; 10: $1239-1249$.

35. Shimizu $\mathrm{Y}$, Nagaya N, Teranishi $\mathrm{Y}$, Imazu M, Yamamoto $\mathrm{H}$, Shokawa T, et al. Ghrelin improves endothelial dysfunction through growth hormone-independent mechanisms in rats. Biochem Biophys Res Commun 2003; 310: 830-835.

36. Solomon A, De Fanti BA, Martinez JA. The nucleus tractus solitari (NTS) participates in peripheral ghrelin glucostatic hunger signalling mediated by insulin. Neuropeptides 2006; 40: 169-175.

37. Guyenet PG. The sympathetic control of blood pressure. Nat Rev Neurosci 2006; 7: 335-346.

38. Waki H, Gouraud SS, Maeda M, Paton JF. Evidence of specific inflammatory condition in nucleus tractus solitarii of spontaneously hypertensive rats. Exp Physiol 2010; 95: 595-600.

39. Paton JF, Wang S, Polson JW, Kasparov S. Signalling across the blood brain barrier by angiotensin II: Novel implications for neurogenic hypertension. J Mol Med 2008; 86: 705-710.

40. Campagnole-Santos MJ, Diz DI, Ferrario CM. Baroreceptor reflex modulation by angiotensin II at the nucleus tractus solitarii. Hypertension 1988; 11: I167-I171.

41. Zanutto BS, Valentinuzzi ME, Segura ET. Neural set point for the control of arterial pressure: Role of the nucleus tractus solitarius. Biomed Eng Online 2010; 9: 4.

42. Skoczylas A, Adamczak M, Chudek J, Wiecek A. Cilazapril increases plasma ghrelin concentration in obese patients with arterial hypertension. Endokrynol Pol 2010; 61: 21-27.

43. Ukkola $\mathrm{O}$. Ghrelin in type 2 diabetes mellitus and metabolic syndrome. Mol Cell Endocrinol 2011; 340: 26-28.

44. Ribeiro RT, Afonso RA, Macedo MP. Hepatic parasympathetic role in insulin resistance on an animal model of hypertension. Metabolism 2007; 56: 227-233.

45. Miesel A, Muller H, Thermann M, Heidbreder M, Dominiak P, Raasch W. Overfeeding-induced obesity in spontaneously hypertensive rats: An animal model of the human metabolic syndrome. Ann Nutr Metab 2010; 56: 127-142. 